\title{
AtTITUDES TO CHEMICALS AND PESTICIDES
}

T he Health Promotion Unit of Hornsby Ku-ring-gai

Hospital and Community Health Services has investigated householders' attitudes and behaviour relating to household chemicals and pesticides.

A survey was conducted between May and June 1991 among residents in the Hornsby Shire and the Kuring-gai Municipal Council areas, which are serviced by the Hornsby Ku-ring-gai Hospital and Community Health Services. Two thousand questionnaires were sent to a randomly selected sample of residents aged 18 years and over. A total of 994 residents returned the survey, which represents a 49.7 per cent response rate. A report on the results of the survey has been produced ${ }^{1}$.

The main issues revealed in the report are as follows:

- There are concerns about the effects of household chemicals and pesticides on families and the environment. However, there is greater concern about the impact of pesticides.

Some people have experienced health problems associated with household chemicals and pesticides. There are misconceptions about the hazard level of household chemicals and pesticides. In particular, cleaning agents were perceived as least hazardous to the family as well as to the environment. People are aware of alternatives to household chemicals and pesticides, and alternative methods for pest control. Many people would use alternatives if they were cheap and effective, but there are still misconceptions about what constitutes a "safer" alternative.

- There is still a need for people to be informed about where to get information and assistance on household chemicals and pesticides.

People want more information and education about household chemicals and pesticides. The media have played a vital role in raising community awareness, as they are perceived to be a major source of information and education.

In relation to specific behaviours:

$\square$

Many people do not safely store their household chemicals and pesticides. For example, chemicals are stored in unlocked cupboards which are accessible to children.

$\square$ People reported storing chemicals in their original containers and do not reuse containers for other storage purposes.

Most people reported being cautious when using household chemicals and pesticides. They read labels, follow safety directions and wear protective clothing and they do not use them around children, pets, food or food preparation areas.

People disposed of chemicals and their containers in the garbage and were unaware of other provisions for disposal, such as chemical disposal days. Many people have changed the way they use chemicals, especially over the past two years. They report using fewer chemicals, using alternatives and having stopped using some chemicals.

Few people reported having their dwelling regularly sprayed for pests and most did not take action until there were signs of problems with pests.

More information and education would raise awareness of chemical and pesticide issues, dispel misconceptions and encourage safe practices. This may lead to a safer household environment and reduce the potential for accidents and injuries with household chemicals and pesticides. For further information about the report, contact the Health Promotion Unit on (02) 4499144.

1. Krolik P, Piper D, McKenna G. Household Chemicals and Pesticides: A Study of Community Attitudes and Behowiour. Sydney, Health Promotion Unit, Hornsby Ku-ring-gai Hospital, 1992.

\section{EDITORIAL NOTE}

A significant proportion of domestic chemicals is not subject to any formal review mechanism before marketing in Australia. To gain some insight into how often and why accidental poisoning by domestic chemicals occurs, a National Health and Medical Research Council Working Party on Domestic Chemicals was instructed to prepare a National Plan for Domestic Chemicals. This plan was completed in August 1991.

Two studies ${ }^{2,3}$ were commissioned by the working party. The first was a national survey of 2,677 people aged 14 years and over which involved qualitative and quantitative research into the hazards of domestic chemicals, with particular emphasis on the community's awareness, understanding and behaviour associated with domestic chemicals. In addition, 500 households within this sample were audited to identify actual behaviour (compared to stated behaviour) with regard to the perceived hazards associated with common domestic chemicals. This survey found that the risks of a range of domestic chemicals were likely to be underestimated. In 90 per cent of homes at least one chemical product rated as being highly hazardous was being stored unsafely. This proportion fell only slightly (to 84 per cent) in households frequented by under 4-year-olds where the household heads reported they always read label information and always take danger warnings seriously.

The second study was a follow-up survey of 1,455 calls to the NSW Poisons Information Centre. A significant number of these calls related to potentially serious poisonings as judged by the toxicity of the substance involved. The report concluded that many of the accidents were preventable. The importance of packaging and labelling in the prevention of accidental poisoning was emphasised.

The findings of this study in Hornsby Shire and Kuring-gai Municipal Council areas are in agreement with the selfreported perceptions of participants in the national survey, but the discordance with actual behaviour underlines the need to raise awareness about the hazards of these chemicals in the home.

Important recommendations of the working party were:

\begin{tabular}{l|l} 
To develop a common hazard identification system \\
for domestic chemicals based on easily identifiable \\
symbols, supported by education and training \\
schemes; \\
To extend the use of child-resistant containers \\
where appropriate; \\
To improve surveillance of accidental poisoning \\
in the domestic environment; and \\
To obtain agreement from industry to provide \\
product formulation details and to employ a \\
uniform hazard identification system.
\end{tabular}

These recommendations address some of the structural impediments to reducing accidental poisoning in the home and complement those in the North Sydney report.

1. A National Plan for Domestic Chemicals. A Report of the NH\&MRC Working Party Report to the Public Health Committee. August 1991 2. Corbett SJ, Williamson M, Harrison J. Accidental Poisoning in the Domestic Environment. Report to the NH\&MRC Working Party on Domestic Chemicals. July 1991.

3. Reark Research National Survey of Chemicals Used in the Home and the Community's Understanding of the Hazards of Domestic Chemicals. 